\title{
Clay exfoliation and polymer/clay aerogels by supercritical carbon dioxide
}

\author{
Simona Longo ${ }^{1}$, Marco Mauro ${ }^{1}$, Christophe Daniel ${ }^{1}$, Maurizio Galimberti ${ }^{2,3}$ and Gaetano Guerra ${ }^{1 *}$ \\ ' Department of Chemistry and Biology and INSTM Research Units, Università degli Studi di Salerno, Fisciano, Italy \\ ${ }^{2}$ Department of Chemistry, Materials and Chemical Engineering, Politecnico di Milano, Milano, Italy \\ ${ }^{3}$ CNR, Istituto per lo Studio delle Macromolecole, National Research Council, Milano, Italy
}

\section{Edited by:}

Giuseppe Mensitieri, University of Naples Federico II, Italy

\section{Reviewed by:}

Giuseppe Mensitieri, University of

Naples Federico II, Italy

Ernesto Di Maio, University of

Naples Federico II, Italy

Giovanni Filippone, University of

Naples Federico II, Italy

\section{*Correspondence:}

Gaetano Guerra, Department of Chemistry and Biology and INSTM Research Units, Università degli Studi di Salerno, Via Giovanni Paolo II 132, 84084 Fisciano, Italy e-mail:gguerra@unisa.it

Supercritical carbon dioxide $\left(\mathrm{scCO}_{2}\right)$ treatments of a montmorillonite (MMT) intercalated with ammonium cations bearing two long hydrocarbon tails (organo-modified MMT, OMMT) led to OMMT exfoliation, with loss of the long-range order in the packing of the hydrocarbon tails and maintenance of the long-range order in the clay layers. The intercalated and the derived exfoliated OMMT have been deeply characterized, mainly by X-ray diffraction analyses. Monolithic composite aerogels, with large amounts of both intercalated and exfoliated OMMT and including the nanoporous-crystalline $\delta$ form of syndiotactic polystyrene (s-PS), have been prepared, by $\mathrm{scCO}_{2}$ extractions of s-PS-based gels. Also for high OMMT content, the gel and aerogel preparation procedures occur without re-aggregation of the exfoliated clay, which is instead observed for other kinds of polymer processing. Aerogels with the exfoliated OMMT have more even dispersion of the clay layers, higher elastic modulus and larger surface area than aerogels with the intercalated OMMT. Extremely light materials with relevant transport properties could be prepared. Moreover, s-PS-based aerogels with exfoliated OMMT could be helpful for the handling of exfoliated clay minerals.

Keywords: cationic clays, organoclays, montmorillonite, syndiotactic polystyrene, nanoporous-crystalline $\delta$ form, monolithic aerogels

\section{INTRODUCTION}

Over the last decades, clay polymer nanocomposites (CPN) (LeBaron et al., 1999; Alexandre and Dubois, 2000; Ray and Okamoto, 2003; Bergaya, 2008; Chen et al., 2008; Galimberti, 2011) have been steadily increasing their importance in the field of material science, as they substantially improve polymer properties such as mechanical reinforcement, impermeability, thermal stability (Paul and Robeson, 2008; Bergaya and Lagaly, 2013). Superior properties are achieved when individual clay layers or stacks of few layers are evenly distributed in the polymer matrix and polymer-clay interfaces are maximized (Kojima et al., 1993; Vaia et al., 1993; Manias et al., 2001).

CPN exhibiting exfoliated clays are difficult to attain, particularly in the case of non-polar polymers (Choi et al., 2004; Robello et al., 2004; Chou and Lin, 2005; Galimberti et al., 2007, 2009, 2010).

Many reports show that different processing techniques based on supercritical carbon dioxide $\left(\mathrm{scCO}_{2}\right)$ constitute effective ways to increase dispersion and delamination in polymer/clay nanocomposites (Ma et al., 2007; Nguyen and Baird, 2007; Treece and Oberhauser, 2007; Samaniuk et al., 2009; Baker et al., 2011; Feng-hua et al., 2011; Chen et al., 2012). However, X-ray characterization of most samples show the presence of basal $00 \mathrm{l}$ reflections, clearly indicating that treatments with $\mathrm{scCO}_{2}$ are generally unsui to induce complete organoclay exfoliation (Ma et al., 2007; Nguyen and Baird, 2007; Treece and Oberhauser, 2007; Samaniuk et al., 2009; Thompson et al., 2009; Baker et al., 2011; Feng-hua et al., 2011; Chen et al., 2012).
Only some reports, from the Kannan's group, show that a complete disappearance of the $00 \mathrm{l}$ reflections (and hence a complete exfoliation) can be achieved by $\mathrm{scCO}_{2}$ treatments on pure organoclays, where alkali counterions have been exchanged with long-chain alkylammoniums (Horsch et al., 2006; Manitiu et al., 2008). However, as a consequence of preparation of polymer nanocomposites, the $00 l$ reflections reappear with peak height and location essentially independent of the processing conditions (Manitiu et al., 2008).

$\mathrm{scCO}_{2}$ treatments are also effective to prepare monolithic aerogels, by drying of wet gels. Aerogels constitute a unique class of materials, characterized by a highly porous network being attractive for many applications such as thermal and acoustic insulation, capacitors or catalysis (Kistler, 1931; Schaefer and Keefer, 1986; Anderson et al., 2002; Malik et al., 2006; Wei et al., 2010; Kucheyev et al., 2012; Longo et al., 2013). In recent years, the $\mathrm{scCO}_{2}$ extraction of gels of suitable thermoplastic polymers, like syndiotactic polystyrene (s-PS) (De Rosa et al., 1997; Milano et al., 2001; Gowd et al., 2006; Rizzo et al., 2007; Petraccone et al., 2008) and poly(2,6-dimethyl-1,4-phenylene)oxide, (Daniel et al., 2011, 2013a,b; Galizia et al., 2012; Tarallo et al., 2012) has allowed the preparation of a special class of monolithic aerogels, (Daniel et al., 2005, 2008, 2009, 2012, 2013a,b; Wang and Jana, 2013) that present, beside disordered amorphous micropores (typical of all aerogels), identical nanopores of nanoporous-crystalline phases. Many studies show that nanoporous-crystalline polymer phases are able to absorb low molecular-mass molecules also when present in traces and are suitable for molecular separation 
(Manfredi et al., 1997; Musto et al., 2002; Mahesh et al., 2005; Venditto et al., 2006; Albunia et al., 2013), sensor (Mensitieri et al., 2003; Giordano et al., 2005; Cusano et al., 2006; Buono et al., 2009; Pilla et al., 2009; Erdogan et al., 2012) and catalysis (Buonerba et al., 2012) applications.

A first aim of the present paper is a deeper investigation of the $\mathrm{scCO}_{2}$ induced organoclay exfoliation, by a more complete X-ray diffraction characterization of organoclays before and after $\mathrm{scCO}_{2}$ treatments. The second aim of the paper is the preparation of composite aerogels containing large amounts of exfoliated organoclay as well as a nanoporous-crystalline polymer phase. The basic idea is that aerogel preparation processes, also based on $\mathrm{scCO}_{2}$ extraction, could help to maintain the clay exfoliation, which is generally lost in the nanocomposite processing (Manitiu et al., 2008). Advanced properties are pursued, through the synergy of aerogels and exfoliated clays. A montmorillonite (MMT) intercalated with dimethyl di(hydrogenated tallow) (2HT) ammonium cation was selected as the organoclay (OMMT in the following).

\section{MATERIALS AND METHODS \\ MATERIALS}

Organically modified MMT, trade name Dellite ${ }^{\circledR}$ 67G, with 40 wt $\%$ of di(hydrogenated tallow)-dimethylammonium (2HT) was purchased from Laviosa Chimica Mineraria S.p.A.

The sPS used in this study was manufactured by Dow Chemicals under the trademark Questra $101 .{ }^{13} \mathrm{C}$ nuclear magnetic resonance characterization showed that the content of syndiotactic triads (Grassi et al., 1987) was over 98\%. The mass average molar mass obtained by gel permeation chromotography (GPC) in trichlorobenzene at $135^{\circ} \mathrm{C}$ was found to be $M_{w}=$ $3.2 \times 10^{5} \mathrm{~g} \mathrm{~mol}^{-1}$ with a polydispersity index $M_{w} / M_{n}=3.9$.

1,2-dichlorobenzene (DCB), used for clay dispersions, was purchased from Aldrich and used without further purification.

\section{CLAY DELAMINATION AND EXFOLIATION BY $\mathrm{ScCO}_{\mathbf{2}}$}

Exfoliated clay samples were obtained by using a SFX 200 supercritical carbon dioxide extractor (ISCO Inc.). Organically modified clays (typically $10 \mathrm{mg}$ in a $20 \mathrm{~mL}$ stainless steel vessel) were processed in $\mathrm{scCO}_{2}$ at $40^{\circ} \mathrm{C}$ and $200 \mathrm{bar}$, for 16 and $32 \mathrm{~h}$ under quiescent conditions, in order to promote the diffusion of the supercritical fluid into the clay interlayer space. The system was then rapidly depressurized $(1 \mathrm{~min})$ to atmospheric pressure and the expansion of the $\mathrm{scCO}_{2}$ between the layers caused the clay exfoliation.

\section{PREPARATION OF sPS/CLAY GELS}

Dispersions of the clays in DCB were obtained with both as received and exfoliated samples. A clay dispersion was initially prepared by adding the appropriate clay amount in $5 \mathrm{ml}$ of DCB. The mixtures were homogenized for $1 \mathrm{~h}$ under magnetic stirring and sonicated in a $5000 \mathrm{~mL}$ batch bath ultrasound (Badelin Sonorex RK $1028 \mathrm{H}$ ) for $1 \mathrm{~h}$.

sPS/clay gels were prepared, in hermetically sealed test tubes, by heating the clay dispersions above the boiling point of the solvent until complete dissolution of the polymer and the appearance of a transparent and homogeneous solution had occurred.
The hot solution was then cooled to room temperature, where gelation occurred. For instance, $655 \mathrm{mg}$ of sPS and $5 \mathrm{~mL}$ of $2 \mathrm{wt}$ $\%$ clay dispersion were mixed to obtain clay/polymer gels. The overall amount of polymer and clay in the gels was generally fixed to $10 \mathrm{wt} \%$.

\section{PREPARATION OF SPS/CLAY AEROGELS}

Aerogels were obtained by treating sPS/clay gels with a SFX 200 supercritical carbon dioxide extractor (ISCO Inc.) using the following conditions: $T=40^{\circ} \mathrm{C}, P=200 \mathrm{bar}$, extraction time $t=$ $6 \mathrm{~h}$. The prepared s-PS/clay aerogels present a weight composition ranging between $96 / 4$ and 50/50. The aerogels, as prepared from gels with an overall polymer-clay content of $10 \mathrm{wt} \%$, present a porosity close to $90 \%$.

For monolithic aerogels with a regular cylindrical shape, the total porosity can be estimated from the mass/volume ratio of the aerogel. Then, the percentage of porosity $P$ of the aerogel samples can be expressed as:

$$
P=100 *\left[1-\left(\rho_{\text {app }} / \rho_{\text {pol }}\right)\right]
$$

where $\rho_{\text {pol }}$ is the density of the polymer matrix and $\rho_{\text {app }}$ is the aerogel apparent density calculated from the mass/volume ratio of the monolithic aerogels.

\section{CHARACTERIZATION TECHNIOUES \\ Wide angle $X$-ray diffraction}

Wide-angle X-ray diffraction (WAXD) patterns with nickel filtered $\mathrm{Cu}-\mathrm{K} \alpha$ radiation were obtained, with an automatic Bruker D8 Advance diffractometer, in reflection. The intensities of the WAXD patterns were not corrected for polarization and Lorentz factors, to allow an easier comparison with most literature data. The $D_{\text {hkl }}$ correlation length of crystals was determined applying the Scherrer equation:

$$
D_{\mathrm{hkl}}=K \lambda /\left(\beta_{\mathrm{hkl}} \cos \theta_{\mathrm{hkl}}\right)
$$

where: $K$ is the Scherrer constant, $\lambda$ is the wavelength of the irradiating beam $(1.5419 \AA, \mathrm{CuK} \alpha), \beta_{\mathrm{hkl}}$ is the width at half height, and $\theta_{\mathrm{hkl}}$ is the diffraction angle. The instrumental broadening, $b$, was determined by obtaining a WAXD pattern of a standard silicon powder 325 mesh (purity $>99 \%$ ), under the same experimental conditions. For each observed reflection with $\beta_{\mathrm{hkl}}<1^{\circ}$, the width at half height was evaluated by subtracting the unavoidable instrumental broadening of the closest silicon reflection from the experimental width at half height, $\beta_{\mathrm{hkl}}$, using the following relationship:

$$
\beta_{\mathrm{hkl}}^{2}=\left(B_{\mathrm{hkl}}^{2}-b^{2}\right)
$$

\section{Scanning electron microscopy}

The internal morphology of the aerogels was characterized by means of a scanning electron microscope (SEM, Zeiss Evo50 equipped with an Oxford energy dispersive X-ray detector). Samples were prepared by fracturing small pieces of the monoliths in order to gain access to the internal part of the specimen. In fact, the external lateral surfaces of most samples were found to 
be flat and free of porosity. Low energy was used ( $5 \mathrm{keV})$ to obtain the highest possible surface resolution. Before imaging, all specimens were coated with gold using a VCR high resolution indirect ion-beam sputtering system. The samples were coated depositing approximately $20 \mathrm{~nm}$ of gold. The coating procedure was necessary to prevent surface charging during measurement and to increase the image resolution.

\section{BET measurements}

Nitrogen adsorption at liquid nitrogen temperature $(77 \mathrm{~K})$ was used to measure surface areas of OMMT and polymer/OMMT aerogels with a Nova Quantachrome 4200e instrument. Before the adsorption measurement, OMMT powders were degassed at $100^{\circ} \mathrm{C}$ under vacuum for $24 \mathrm{~h}$, while polymer/clay aerogels were degassed at $40^{\circ} \mathrm{C}$, in the same conditions. The surface area values were determined by using 11-point BET analysis.

\section{Differential scanning calorimetry}

The differential scanning calorimetry (DSC) of OMMT powders and polymer/OMMT aerogels was carried out under nitrogen from 0 to $300^{\circ} \mathrm{C}$ at a heating rate of $10^{\circ} \mathrm{C} / \mathrm{min}$ on a TA instruments DSC 2920.

\section{Dynamic-mechanical analysis}

Dynamic-mechanical properties were studied using a Triton dynamic-mechanical thermal analyzer. The spectra were recorded in the three-point bending mode, on samples with the following dimensions: length $15 \mathrm{~mm}$, width $10 \mathrm{~mm}$, and thickness $2 \mathrm{~mm}$. The modulus $E^{\prime}$ was obtained, as a function of temperature, at a frequency of $1 \mathrm{~Hz}$ and an amplitude of $0.03 \mathrm{~mm}$. The heating rate was $2^{\circ} \mathrm{C} / \mathrm{min}$ in the range of $0,+100^{\circ} \mathrm{C}$.

\section{RESULTS AND DISCUSSION OMMT EXFOLIATION BY ScCO}

The X-ray diffraction $(\mathrm{CuK} \alpha)$ pattern in the $2 \vartheta$ range $2-80^{\circ}$ of the OMMT, with $40 \mathrm{wt} \%$ of $2 \mathrm{HT}$, is reported in Figure 1A. Besides many $00 l$ reflections (up to $l=12$ ) that indicate a high degree of order perpendicular to the clay layers and an interlayer spacing of $3.5 \mathrm{~nm}$, the pattern shows well defined weak peaks, corresponding to the typical 020, 210, and 060 in-plane MMT periodicities (Galimberti et al., 2007; Powder diffraction database 70-2151 International Centre for Diffraction Data, 1999). It is worth adding that a well defined narrow peak is also present at $2 \vartheta=21.7^{\circ}$, corresponding to $d=$ $0.41 \mathrm{~nm}$, i.e., the distance between long hydrocarbon chains in their rotator order, analogous to those observed for longchain alkylammoniums intercalated in anionic clays (layered double hydrotalcite, LDH) (Itoh et al., 2003) as well as in graphite oxide (Mauro et al., 2013) The thickness of the clay layer $(\approx 1 \mathrm{~nm})$ and the length of the alkylammoniums $(\approx 5 \mathrm{~nm})$ (Osman et al., 2002) indicate that the tilting angle of the hydrocarbon chains is not far from $\alpha=60^{\circ}$. Hence, the X-ray diffraction pattern of Figure 1A indicates the presence of a MMT/2HT intercalate structure, whose schematic projections, parallel and perpendicular to the clay layers, are shown in Figures 2A,B, respectively.

The X-ray diffraction patterns of the OMMT of Figure 1A, after short term and long term treatments by $\mathrm{scCO}_{2}$ are shown in Figures 1B,C, respectively. For the intermediate pattern of Figure 1B, the intensities of the $00 l$ peaks as well as of the rotator order peak (100r) are strongly reduced (see also the inset of Figure 1B). The in-plane 020, 210, and 060 peaks maintain their intensity and narrowness. This indicates that short term

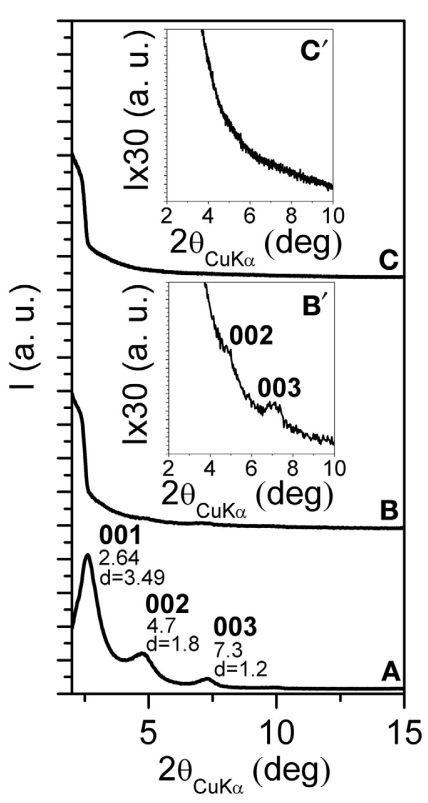

FIGURE 1 | X-ray diffraction (CuK $\alpha$ ) patterns in the $2 \vartheta$ range $2-80^{\circ}$ of MMT, as intercalated with $40 \mathrm{wt} \%$ of $2 \mathrm{HT}$ ammonium before (A) and after $16 \mathrm{~h}$ (B) and $32 \mathrm{~h}$ (C) $\mathrm{scCO}_{2}$ treatments. The inset in (B) and (C)

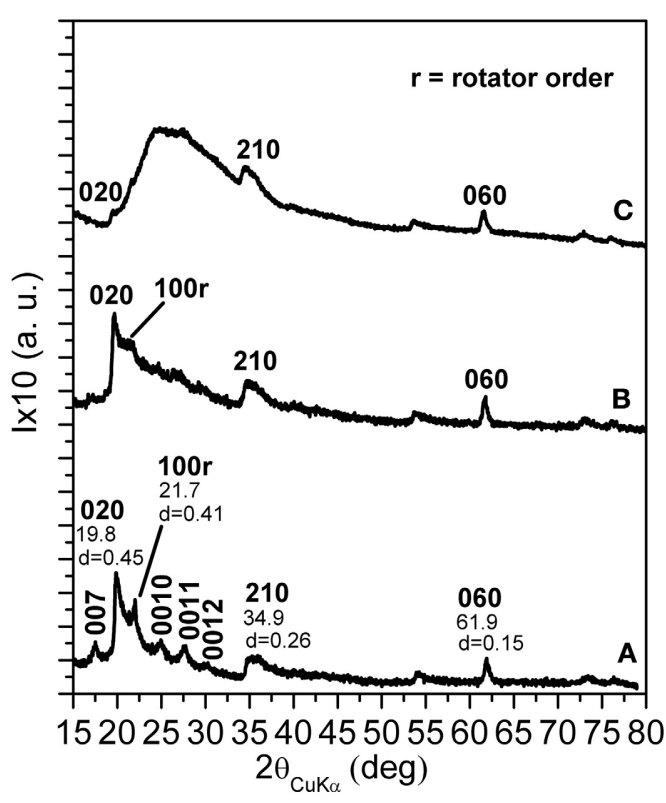

enlarges the $2 \vartheta$ range $2-10^{\circ}$. The Miller index $100 \mathrm{r}$ indicate the reflection relative to the rotator order of the long hydrocarbon chains within the interlayer space. 


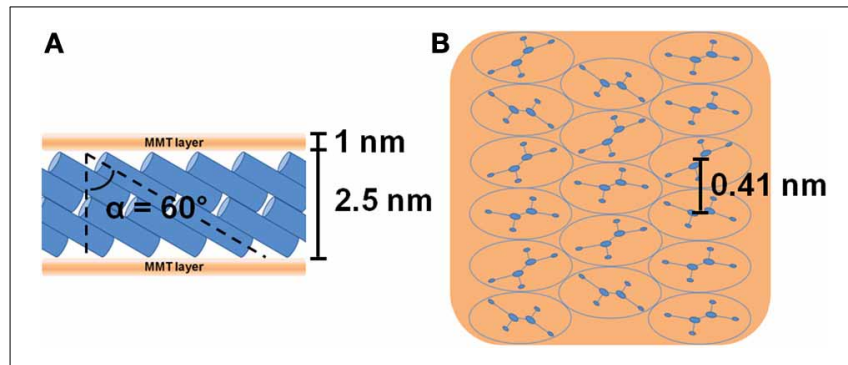

FIGURE 2 | Schematic projections parallel (A) and perpendicular (B) to the clay layers of the starting $\mathrm{MMT} / 2 \mathrm{HT}$ (OMMT) intercalate structure. The hydrocarbon tails of the ammonium cations are represented as cylinders in the lateral view (A) and as ellipses in the top view (B). The distance between the axes of adjacent cylinders $(0.41 \mathrm{~nm})$ is shown in (B) while the definition of the alkyl chains tilt angle is shown in (A).

$\mathrm{scCO}_{2}$ treatments lead to a nearly complete clay exfoliation with maintenance of the in-plane order.

In agreement with previous results (Manitiu et al., 2008), the $\mathrm{X}$-ray diffraction pattern of the OMMT, after long-term $\mathrm{scCO}_{2}$ treatments, does not show anymore the $00 \mathrm{l}$ reflections (see also the inset of Figure 1C): clay exfoliation is achieved. It is worth adding that the in-plane 020,210 , and 060 reflections are still present, although become less intense than a broad amorphous halo that appears in the $2 \theta$ range $20-30^{\circ}$. This amorphous halo can be attributed to a loss of order in the stacking of the clay layers, also associated with a complete loss of order in the packing of the hydrocarbon tails.

In summary, the described long-term $\mathrm{scCO}_{2}$ treatments lead to exfoliation of the OMMT, and to a complete loss of long-range lateral order of the hydrocarbon tails of the cationic surfactant. The maintenance of hk0 reflections (mainly of the isolated 060 reflection), not yet reported in the literature, assures the maintenance of a long-range order in the clay layers. In this respect, it is worth adding that the half-height width of the 060 reflection, after exfoliation, remains equal to $0.45^{\circ}$ indicating a correlation length $D_{060}=28 \mathrm{~nm}$.

Relevant additional information, relative to the as received and $\mathrm{scCO}_{2}$-treated OMMT, can be obtained by DSC scans (Figure 3 ). The scan of the as received OMMT (Figure 3A) presents a reversible transition nearly located at $44^{\circ} \mathrm{C}(\Delta \mathrm{H} \approx 26 \mathrm{~J} / \mathrm{g})$ that corresponds to the loss of rotator order of the hydrocarbon tails of the cations intercalated in the interlayer space. In this respect, it is worth adding that endothermic peaks corresponding to the loss of order in the packing of the hydrocarbon tails have been observed, in the temperature range $25-80^{\circ} \mathrm{C}$, not only for cationic organoclays, (Cipolletti et al., 2013) but also for other organically modified layered inorganic structures (Ide and Ogawa, 2006) as well as for graphite oxide intercalation compounds (Mauro et al., 2013). The DSC scan of the $\mathrm{scCO}_{2}$ treated OMMT does not present any thermal transition in the considered temperature range (Figure 3B) and hence indicates the loss of $3 \mathrm{D}$ order in the packing of the hydrocarbon tails of the ammonium surfactant, which is compatible with clay exfoliation.

The overall information arising from X-ray diffraction and DSC characterization allows to conclude that the as received

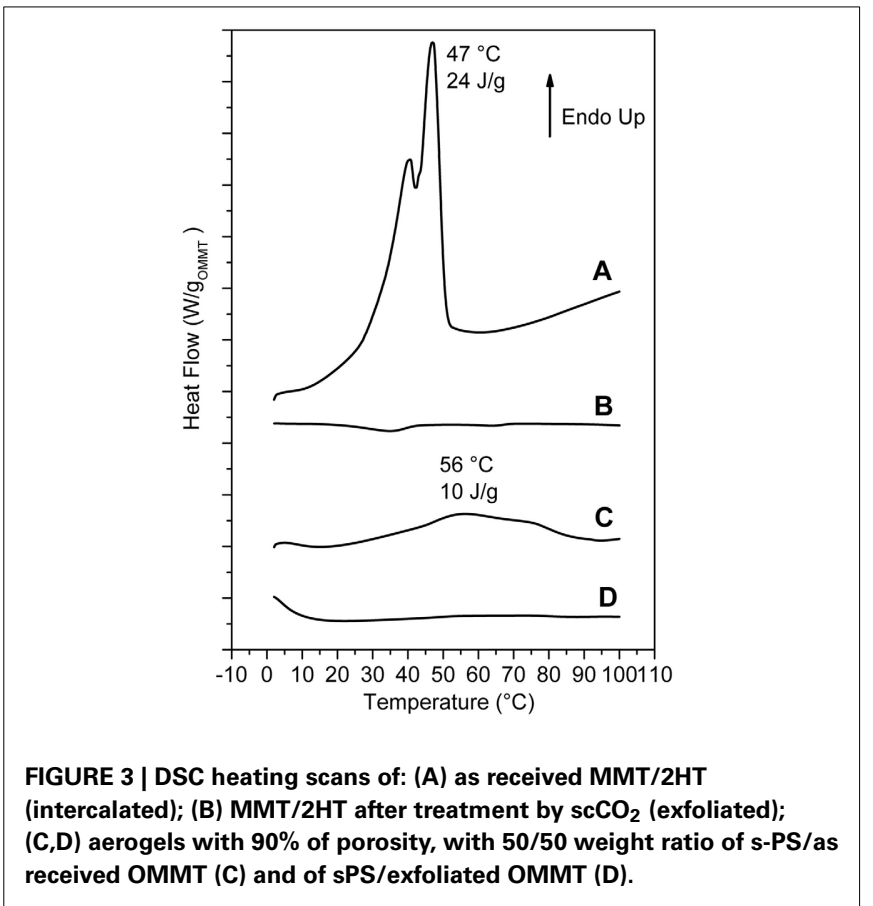

and $\mathrm{scCO}_{2}$ treated OMMT can be described as intercalated and exfoliated OMMT, respectively.

\section{MONOLITHIC NANOPOROUS-CRYSTALLINE S-PS AEROGELS WITH LARGE OMMT CONTENT}

Monolithic composite aerogels, filled with large fractions of intercalated and exfoliated OMMT, have been prepared by using an s-PS matrix. This polymer choice is mainly due to the ability of s-PS to produce monolithic aerogels in a very broad range of porosity (from 50\% up to 99\%). An additional reason for this choice is the easy obtainment of aerogels exhibiting s-PS nanoporous-crystalline $\delta$ (Daniel et al., 2005, 2008) or $\varepsilon$ (Daniel et al., 2009) phases.

Aerogels with a porosity of nearly $90 \%$ were obtained by $\mathrm{scCO}_{2}$ extraction of gels with a DCB content of $90 \mathrm{wt} \%$ and with different s-PS/OMMT weight ratios. For all aerogels with polymer/OMMT ratio equal or higher than 80/20, monolithic structures were obtained. Moreover, as usual for s-PS based aerogels, (Daniel et al., 2005, 2008, 2009, 2012, 2013a,b) the size and shape of s-PS/clay aerogels are essentially the same of the precursor gels. Aerogels with a 50/50 polymer/OMMT ratio are brittle and are generally obtained as powders.

X-ray diffraction $(\mathrm{CuK} \alpha)$ patterns of s-PS based aerogels, containing intercalated and exfoliated OMMT, are shown in Figures 4, 5, respectively.

All patterns of Figure 4 show the typical reflections of the nanoporous-crystalline $\delta$ form. In particular, the isolated intense 010 reflection is always clearly apparent and located at $2 \theta \approx$ $8.4^{\circ}$. The $00 \mathrm{l}$ reflections of the OMMT are not detected for the aerogels with low clay content (4 and 8 wt \%) while for higher clay contents (20 and $50 \mathrm{wt} \%$ ) a narrow and intense 001 reflection is present, while the 002 and 003 reflections of the starting clay have disappeared. Moreover, the 


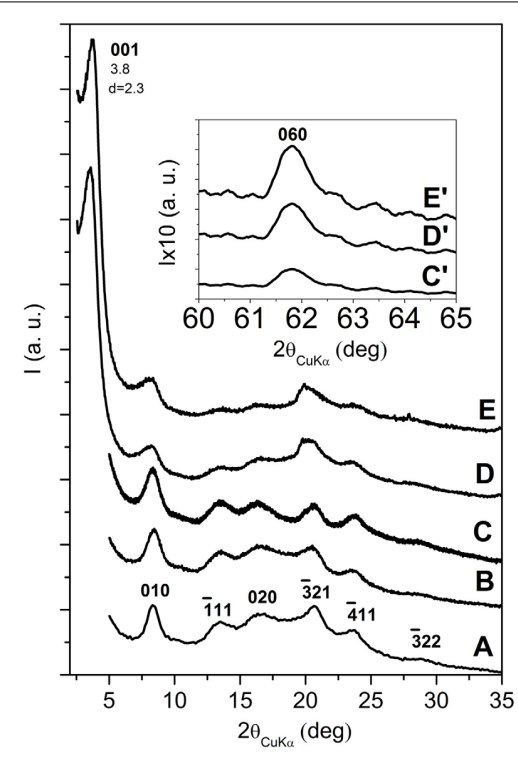

FIGURE 4 | X-ray diffraction (CuK $\alpha$ ) patterns in the $2 \vartheta$ range $2-35^{\circ}$ of s-PS aerogels with as received OMMT, as obtained from gels with a solvent content of $\mathbf{9 0} \mathbf{w t} \%$ and presenting different polymer/OMMT weight ratios: (A) 100/0; (B) 96/4; (C) 92/8; (D) 80/20; (E) 50/50. The insets $C^{\prime}, D^{\prime}$ and $E^{\prime}$ enlarge the 060 in-plane reflection of the clay. The Miller indexes of the main reflections of the nanoporous-crystalline $\delta$ form of s-PS are indicated in (A)

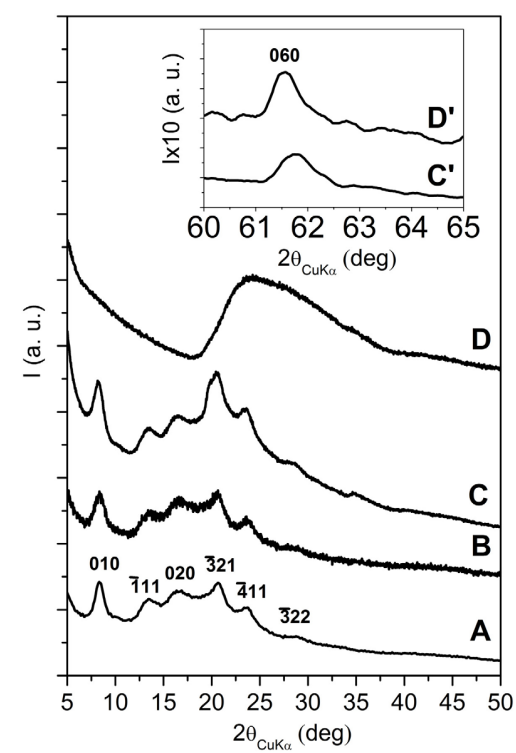

FIGURE 5 | X-ray diffraction (CuK $\alpha$ ) patterns in the $2 \vartheta$ range $5-50^{\circ}$ of s-PS aerogels with exfoliated OMMT, as obtained from gels with a solvent content of $\mathbf{9 0} \mathbf{w t} \%$ and presenting different polymer/OMMT weight ratios: (A) 100/0; (B) 95/5; (C) 80/20; (D) 50/50. The inset $C^{\prime}, D^{\prime}$ enlarges the 060 in-plane reflection of the clay.

001 reflection is markedly shifted with respect to its original position (from $2 \theta=2.6^{\circ}$ up to $2 \theta=3.8^{\circ}$ ), indicating a decrease of the interlayer spacing from $d=3.5 \mathrm{~nm}$ down to $d=2.3 \mathrm{~nm}$.
The results of Figures $4 \mathrm{~A}-\mathrm{C}$ suggest that the aerogel preparation procedure involving $\mathrm{scCO}_{2}$ extraction, for low OMMT content, could lead to clay exfoliation, as already observed for $\mathrm{scCO}_{2}$ treatment of the neat OMMT in Figure 1. Figures 4C,D show that, for high OMMT content in the aerogels, the used procedure is not suitable to generate OMMT exfoliation but, on the contrary, a reduction of the interlayer spacing is observed. An analogous phenomenon of reduction of interlayer spacing has been recently observed for organoclay extraction with different solvents, like e.g., ethyl acetate (Cipolletti et al., 2013). As suggested in that paper, the observed reduction of basal spacing can be attributed to the extraction of excess cationic surfactant, not being ionically bonded to the negatively charged clay layers, but being simply included in the interlayer space by non-bonded interactions and contributing to the crystalline order of the hydrocarbon tails.

Additional information on the structural organization in the s-PS/OMMT aerogels comes from DSC analyses. In particular, DSC heating scan of a 50/50 by wt. s-PS/as-received-clay aerogel is shown in Figure 3C. The endothermic peak, corresponding to loss of rotator order in the interlayer spacing (Figure 1A) becomes broader and its maximum is shifted up to $50-60^{\circ} \mathrm{C}$, with only a minor reduction of the related enthalpy $\left(\Delta \mathrm{H}_{r} \approx 10 \mathrm{~J} / \mathrm{g} \approx 20\right.$ $\mathrm{J} / \mathrm{gOMMT}$ )

The combined information of the X-ray diffraction patterns of Figures 4C,D and the DSC scans of Figure 3C indicates that, for high clay content, the aerogel preparation procedure brings to a reduction of the OMMT basal spacing $\left(d_{001}\right)$ from $3.5 \mathrm{~nm}$ down to $2.3 \mathrm{~nm}$, with only partial loss of the hydrocarbon rotator order in the interlayer space.

The X-ray diffraction patterns of the s-PS aerogels prepared with the exfoliated OMMT (Figure 5), independently of the aerogel composition, do not show $00 l$ clay reflections, while show the isolated weak 060 in-plane clay reflection (as shown by the inset of Figures $\mathbf{5} \mathbf{C}^{\prime}, \mathbf{D}^{\prime}$ ). This clearly indicates that the gel and aerogel preparation procedures, also for high clay concentrations, allow to maintain clay exfoliation without re-aggregation, as instead observed for other common polymer processing (Nguyen and Baird, 2007; Manitiu et al., 2008).

In this respect, it is worth citing that X-ray diffraction patterns of polymer-clay aerogels as obtained by freeze-drying of polymer solutions including clays (Bandi et al., 2005; Pojanavaraphan et al., 2010, 2011; Wang et al., 2013) show the presence of $00 l$ clay reflections, (Pojanavaraphan et al., 2010; Wang et al., 2013), which exclude the occurrence of exfoliation.

The patterns of Figure 5 also show that s-PS is generally crystallized in the nanoporous $\delta$ form (Figures $5 \mathrm{~A}-\mathrm{C}$ ) while, for the 50/50 polymer/exfoliated-OMMT aerogel, the sPS crystallization does not occur (broad amorphous halo of Figure 5D). This is probably due to the good dispersion of a large amount of exfoliated OMMT, leading to a diluting effect on sPS that reduces its crystallization kinetics. This loss of polymer crystallinity leads to a loss of the typical fibrillar structure, which in turn allows rationalizing the loss of monolithic structure. 


\section{COMPARISON BETWEEN AEROGELS WITH INTERCALATED AND EXFOLIATED OMMT}

This section presents a strict comparison between properties of s-PS monolithic aerogels exhibiting a porosity of $90 \%$ and a OMMT content of $20 \mathrm{wt} \%$, as obtained by using intercalated or exfoliated OMMT, that present the X-ray diffraction patterns shown in Figures 4D, 5C, respectively.

On the basis of quantitative evaluations on the X-ray diffraction patterns, the two aerogels present similar degree of polymer crystallinity $(\approx 40 \%)$. However, aerogels with the exfoliated clay (Figure 6A) are much more homogeneous than aerogels obtained with the intercalated OMMT (Figure 6B), which clearly present rough surfaces.

Also the SEM images of the two aerogels are completely different. In fact, the SEM of the aerogel including the intercalated OMMT is dominated by the micrometric OMMT particles (Figure 7B) while the SEM of the aerogel including the exfoliated OMMT (Figure 7A) clearly shows both nanometric clay platelets and nanometric s-PS fibrils (Figure $7 \mathbf{A}^{\prime}$ ).

The results of the SEM analyses suggest that also the large difference in the visual appearance between the two aerogels of Figure 6 could be due to micrometric and nanometric size of intercalated and exfoliated clays, respectively.

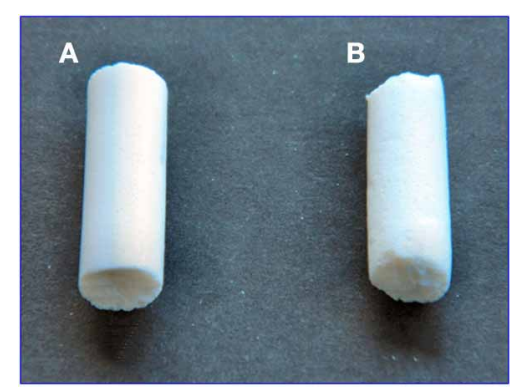

FIGURE 6 | Photographs of cylindrical monolithic (diameter of $7 \mathbf{m m}$ ) s-PS/OMMT aerogels, with porosity $P=90 \%$, as obtained by $\mathbf{s c C O}_{2}$ drying and exhibiting a $\mathbf{8 0 / 2 0}$ weight ratio: (A) with exfoliated clay; (B) with intercalated clay. The shown aerogels essentially present the same size and shape of the precursor gels.

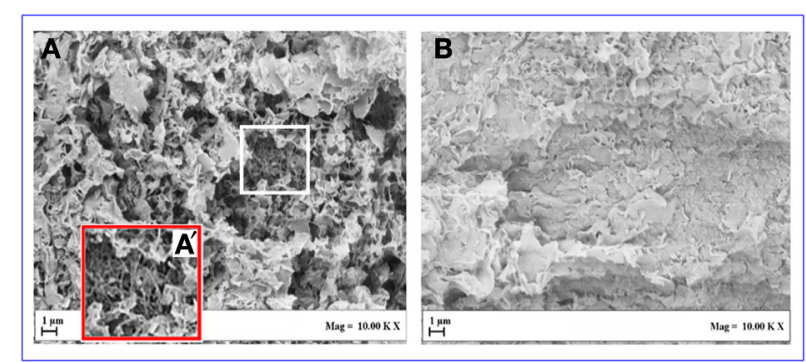

FIGURE 7 | SEM of aerogels with porosity $P=\mathbf{9 0} \%$, having $80 / 20$ polymer/OMMT weight ratio: $\left(A, A^{\prime}\right)$ with exfoliated OMMT; $(B)$ with intercalated OMMT.
DMA analyses indicate that aerogels based on the exfoliated clay present an elastic modulus definitely higher than for those based on intercalated OMMT (36 MPa vs. $15 \mathrm{MPa}$ ).

Surface areas $S_{\mathrm{BET}}$, as obtained by $\mathrm{N}_{2}$ adsorption data at 77 $\mathrm{K}$, for the intercalated and exfoliated OMMT, as well as those of the corresponding aerogels, are compared in Table 1. For the sake of comparison, $S_{\mathrm{BET}}$ of the neat s-PS aerogel presenting the same porosity is shown in the last row of Table 1. As well known, sPS aerogels exhibit high surface areas, mainly associated with the crystalline cavities of the $\delta$ crystalline phase, but also associated with the amorphous aerogel porosity (Daniel et al., 2005, 2008, 2009, 2012, 2013a,b). In agreement with literature data, (Park et al., 2011) $S_{\mathrm{BET}}$ of the OMMT is rather low and is substantially increased for the exfoliated OMMT $\left(S_{\mathrm{BET}}=18 \mathrm{~m}^{2} / \mathrm{g}\right)$. The $\mathrm{s}$-PS/exfoliated-clay aerogels present values of $S_{\mathrm{BET}}\left(281 \mathrm{~m}^{2} \mathrm{~g}^{-1}\right)$ much higher than those of the s-PS/intercalated-clay aerogels $\left(166 \mathrm{~m}^{2} \mathrm{~g}^{-1}\right)$ and not far from those observed for pure s-PS aerogels $\left(312 \mathrm{~m}^{2} \mathrm{~g}^{-1}\right)$. This indicates that, also for this high OMMT content (20 wt \%), the exfoliated clay not only does not disturb the formation of the nanoporous crystalline phase but also does not alter the amorphous aerogel porosity.

A schematic representation of the sPS/exfoliated-OMMT aerogels is shown in Figure 8.

\section{CONCLUSIONS}

A thorough investigation of $\mathrm{scCO}_{2}$-induced exfoliation of OMMTs has been conducted mainly by X-ray diffraction and DSC characterization techniques. The starting material is a MMT intercalated with ammonium cations bearing two long hydrocarbon tails. Suitable $\mathrm{scCO}_{2}$ treatments led to exfoliation of the

Table 1 | Total surface area ( $S_{\mathrm{BET}}$ ) of OMMT samples and of aerogels with porosity $P=90 \%$, having $80 / 20$ polymer/OMMT weight ratio.

\begin{tabular}{ll}
\hline Sample & $\boldsymbol{S}_{\mathrm{BET}^{\mathbf{a}}}\left(\mathbf{m}^{\mathbf{2}} \mathbf{g}^{\mathbf{1}}\right)$ \\
\hline Intercalated OMMT & 10 \\
Exfoliated OMMT (scCO 2 treated) & 18 \\
sPS/intercalated-OMMT, 80/20 aerogel & 166 \\
sPS/exfoliated-OMMT, 80/20 aerogel & 281 \\
Aerogel $\delta$ sPS & 312
\end{tabular}

a Total area evaluated following the BET model in the standard $0.05<P / P_{0}<0.3$ pressure range.

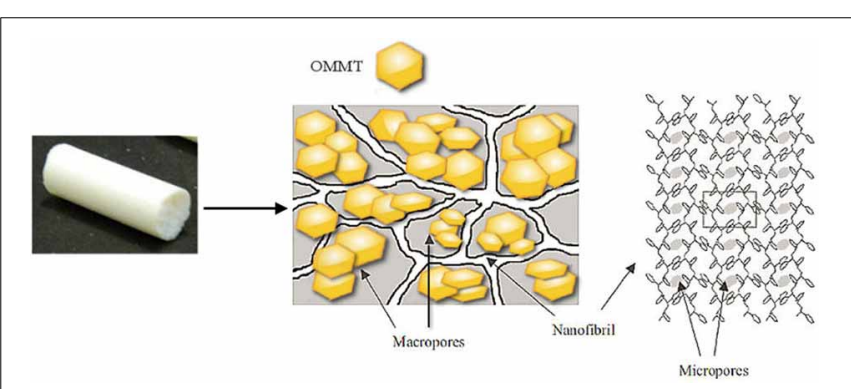

FIGURE 8 | Schematic representation of the sPS/exfoliated-OMMT aerogels. 
OMMT and also led to a complete loss of long-range order in the packing of the hydrocarbon tails of the cationic surfactant. The maintenance of hk0 reflections (mainly of the isolated 060 reflection), not yet reported in the literature, assures the maintenance of a long-range order in the clay layers. DSC scans of the intercalated OMMT present a reversible transition that corresponds to the loss of rotator order of the hydrocarbon chains in the interlayer spacing while those of the exfoliated OMMT do not present any thermal transition up to $100^{\circ} \mathrm{C}$. This confirms the absence of any 3-D order for the exfoliated clay.

Monolithic composite aerogels, filled with large amounts of both intercalated and exfoliated OMMT, have been prepared, starting from s-PS-based gels. In particular, for aerogels with high content of the intercalated OMMT, the preparation procedure brings to a reduction of the basal spacing $\left(d_{001}\right)$ from $3.5 \mathrm{~nm}$ down to $2.3 \mathrm{~nm}$, with only partial loss of the hydrocarbon rotator order in the interlayer space. For aerogels with high content of the exfoliated OMMT, the gel and aerogel preparation procedures allow to maintain clay exfoliation without re-aggregation, as instead observed for other common polymer processing.

A strict comparison between s-PS monolithic aerogels with a porosity of $90 \%$ and a OMMT content of $20 \mathrm{wt} \%$, as obtained by using intercalated or exfoliated OMMT, has been also reported. Although the two aerogels present similar degree of polymer crystallinity $(\approx 40 \%)$ as well as the same polymer crystalline form (the nanoporous-crystalline $\delta$ form), aerogels with the exfoliated OMMT are much more homogeneous than aerogels with the intercalated OMMT. This difference, clearly apparent both on visual inspection as well as on SEM analysis, is due to micrometric and nanometric size of intercalated and exfoliated clays, respectively. Aerogels based on the exfoliated clay also present elastic modulus definitely higher than those based on intercalated OMMT. Moreover, s-PS/exfoliated-clay aerogels present values of surface area $\left(281 \mathrm{~m}^{2} \mathrm{~g}^{-1}\right)$ much higher than those of the sPS/intercalated-clay aerogels $\left(166 \mathrm{~m}^{2} \mathrm{~g}^{-1}\right)$ and not far from those observed for pure s-PS aerogels $\left(312 \mathrm{~m}^{2} \mathrm{~g}^{-1}\right)$. This indicates that, also for high content, the exfoliated clay does not alter the aerogel porosity.

The improvement of properties such as the modulus and the surface area is definitely of interest in view of potential applications of aerogels with exfoliated OMMT, for example for achieving relevant transport properties with extremely light materials. Moreover, the clay rich aerogels (e.g., 50/50, w/w), could be helpful to an easier handling of exfoliated OMMT, removing the risks connected with inhalable nanoparticles.

\section{ACKNOWLEDGMENTS}

We thank Dr. Luca Giannini, Dr. Angela Lostritto and Dr. Valeria Cipolletti of Pirelli Tyre Research Center, for useful discussions. Financial support of 'Ministero dell' Istruzione, dell' Università e della Ricerca” (PRIN) is gratefully acknowledged.

\section{REFERENCES}

Albunia, A. R., Rizzo, P., and Guerra, G. (2013). Control of guest transport in polymer films by structure and orientation of nanoporous-crystalline phases. Polymer 54, 1671-1678. doi: 10.1016/j.polymer.2013.01.027
Alexandre, M., and Dubois, P. (2000). Polymer layered silicate nanocomposites: preparation, properties and uses of a new class of materials. Mater. Sci. Eng. R. Rep. 28, 1-63. doi: 10.1016/S0927-796X(00)00012-7

Anderson, M. L., Stroud, R. M., and Rolison, D. R. (2002). Enhancing the activity of fuel-cell reactions by designing three-dimensional nanostructered architectures, catalyst-modified carbon-silica composite aerogels. Nano Lett. 2, 235-240. doi: $10.1021 / \mathrm{nl} 015707 \mathrm{~d}$

Baker, K. C., Manitiu, M., Bellair, R., Gratopp, C. A., Herkowitz, H. N., and Kannan, R. M. (2011). Supercritical carbon dioxide processed resorbable polymer nanocomposite bone graft substitutes. Acta Biomater. 7, 3382-3389. doi: 10.1016/j.actbio.2011.05.014

Bandi, S., Bell, M., and Schiraldi, D. A. (2005). Temperature-responsive clay aerogel-polymer composites. Macromolecules 38, 9216-9220. doi: $10.1021 / \mathrm{ma0} 051698+$

Bergaya, F., and Lagaly, G. (2013). Handbook of Clay Science. 2nd Edn. Elsevier, Amsterdam.

Bergaya, F. A. (2008). Layered clay minerals: basic research and innovative composite applications. Microp. Mesop. Mater. 107, 141-148. doi: 10.1016/j.micromeso.2007.05.064

Buonerba, A., Cuomo, C., Ortega Sánchez, S., Canton, P., and Grassi, A. (2012). Gold nanoparticles incarcerated in nanoporous syndiotactic polystyrene matrices as new and efficient catalysts for alcohol oxidations. Chem. Eur. J. 18, 709-715. doi: 10.1002/chem.201101034

Buono, A., Rizzo, P., Immediata, I., and Guerra, G. (2009). Detection and memory of nonracemic molecules by a racemic host polymer film. J. Am. Chem. Soc. 129, 10992-10993. doi: 10.1021/ja0732936

Chen, B., Evans, J. R. G., Greenwell, H. C., Boulet, P., Coveney, P. V., Bowden, A. A., et al. (2008). A critical appraisal of polymer-clay nanocomposites. Chem. Soc. Rev. 37, 568-594. doi: 10.1039/b702653f

Chen, C., Samaniuk, J., Baird, D. G., Devoux, G., Zhang, M., Moore, R. B., et al. (2012). The preparation of nano-clay/polypropylene composite materials with improved properties using supercritical carbon dioxide and a sequential mixing technique. Polymer 53, 1373-1382. doi: 10.1016/j.polymer. 2012.01.049

Choi, Y. S., Ham, H. T., and Chung, I. (2004). Effect of monomers on the basal spacing of sodium montmorillonite and the structures of polymer-clay nanocomposites. J. Chem. Mater. 16, 2522-2529. doi: 10.1021/ $\mathrm{cm} 0348601$

Chou, C. C., and Lin, J. (2005). One-step exfoliation of montmorillonite via phase inversion of amphiphilic copolymer emulsion. Macromolecules 38, 230-233. doi: 10.1021/ma047761x

Cipolletti, V., Galimberti, M., Guerra, G., and Mauro, M. (2013). Organoclays with hexagonal rotator order for the paraffinic chains of the compensating cation. Implications on the structure of clay polymer nanocomposites. Appl. Clay Sci. doi: 10.1016/j.clay.2013.11.001

Cusano, A., Iadicicco, A., Pilla, P., Contessa, L., Campopiano, S., Cutolo, A., et al. (2006). Coated long-period fiber gratings as high-sensitivity optochemical sensors. J. Lightw. Technol. 24, 1776-1786. doi: 10.1109/JLT.2006.871128

Daniel, C., Alfano, D., Venditto, V., Cardea, S., Reverchon, E., Larobina, D., et al. (2005). Aerogels with microporous crystalline host phase. Adv. Mater. 17, 1515-1518. doi: 10.1002/adma.200401762

Daniel, C., Giudice, S., and Guerra, G. (2009). Syndiotatic polystyrene aerogels with beta, gamma and epsilon crystalline phases. Chem. Mater. 21, 1028-1034. doi: $10.1021 / \mathrm{cm} 802537 \mathrm{~g}$

Daniel, C., Longo, S., Cardea, S., Vitillo, J. G., and Guerra, G. (2012). Monolithic nanoporous-crystalline aerogels based on PPO. RSC Adv. 2, 12011-12018. doi: $10.1039 / \mathrm{c} 2 \mathrm{ra} 22325 \mathrm{~b}$

Daniel, C., Longo, S., Ricciardi, R., Reverchon, E., and Guerra, G. (2013a). Monolithic nanoporous crystalline aerogels. Macromol. Rapid. Commun. 34, 1194-1207. doi: 10.1002/marc.201300260

Daniel, C., Zhovner, D., and Guerra, G. (2013b). Thermal stability of nanoporous crystalline and amorphous phases of poly(2, 6-dimethyl-1, 4-phenylene)oxide. Macromolecules 46, 449-454. doi: 10.1021/ma302227q

Daniel, C., Longo, S., Vitillo, J. G., Fasano, G., and Guerra, G. (2011). Nanoporous crystalline phases of poly(2, 6-dimethyl-1, 4-phenylene)oxide. Chem. Mater. 23, 3195-3200. doi: 10.1021/cm200546r

Daniel, C., Sannino, D., and Guerra, G. (2008). Syndiotactic polystyrene aerogels: adsorption in amorphous pores and absorption in crystalline nanocavities. Chem. Mater. 20, 577-582. doi: 10.1021/cm702475a 
De Rosa, C., Guerra, G., Petraccone, V., and Pirozzi, B. (1997). Crystal structure of the emptied clathrate form ( $\delta$ form $)$ of syndiotactic polystyrene. Macromolecules 30, 4147-4152. doi: 10.1021/ma970061q

Erdogan, M., Ozbek, Z., Capan, R., and Yagci, Y. (2012). Characterization of polymeric LB thin films for sensor applications. J. Appl. Polym. Sci. 123, 2414-2422. doi: 10.1002/app.34793

Feng-hua, S., Han-xiong, H., and Yang, Z. (2011). Microstructure and mechanical properties of polypropylene/poly(ethylene-co-octene copolymer)/clay ternary nanocomposites prepared by melt blending using supercritical carbon dioxide as a processing aid. Compos. Part B 42, 421-428. doi: 10.1016/j.compositesb.2010.12.005

Galimberti, M. (ed.). (2011). Rubber Clay Nanocomposites-Science, Technology and Applications. New York, NY: Wiley and Sons. doi: 10.1002/9781118092866

Galimberti, M., Giudice, S., Cipolletti, V., and Guerra, G. (2010).Control of organoclay structure in hydrocarbon polymers. Polym. Adv. Tech. 21, 1-6. doi 10.1002/pat. 1757

Galimberti, M., Lostritto, A., Spatola, A., and Guerra, G. (2007). Clay delamination in hydrocarbon rubbers. Chem. Mater. 19, 2495-2499. doi: 10.1021/ $\mathrm{cm} 062782 \mathrm{~m}$

Galimberti, M., Senatore, S., Conzatti, L., Costa, G., Giuliano, G., and Guerra, G. (2009). Formation of clay intercalates with organic bilayers in hydrocarbon polymers. Polym. Adv. Technol. 20, 135-142. doi: 10.1002/pat.1287

Galizia, M., Daniel, C., Fasano, G., Guerra, G., and Mensitieri, G. (2012). Gas sorption and diffusion in amorphous and semicrystalline nanoporous poly(2, 6-dimethyl-1, 4-phenylene)oxide. Macromolecules 45, 3604-3615. doi: $10.1021 / \mathrm{ma} 3000626$

Giordano, M., Russo, M., Cusano, A., Mensitieri, G., and Guerra, G. (2005). Syndiotactic polystyrene thin film as sensitive layer for an optoelectronic chemical sensing device. Sens. Actuators B 109, 177-184. doi: 10.1016/j.snb.2004.02.053

Gowd, E. B., Shibayama, N., and Tashiro, K. (2006). Structural changes in thermally induced phase transitions of uniaxially oriented $\delta_{e}$ form of syndiotactic polystyrene investigated by temperature-dependent measurements of X-Ray fiber diagrams and polarized infrared spectra. Macromolecules 39, 8412-8418 doi: $10.1021 / \mathrm{ma} 061659 \mathrm{~d}$

Grassi, A., Pellecchia, C., Longo, P., and Zambelli, A. (1987). Selective synthesis of syndiotactic polystyrene. Gazz. Chim. Ital. 117, 249-250.

Horsch, S., Serhatkulu, G., Gulari, E., and Kannan, R. M. (2006). Supercritical $\mathrm{CO}_{2}$ dispersion of nano-clays and clay/polymer nanocomposites. Polymer 47, 7485-7496. doi: 10.1016/j.polymer.2006.08.048

Ide, Y., and Ogawa, M. (2006). Preparation and some properties of organically modified layered alkali titanates with alkylmethoxysilanes. J. Colloid. Interface Sci. 296, 141-149. doi: 10.1016/j.jcis.2005.08.058

Itoh, T., Ohta, N., Shichi, T., Yui, T., and Takagi, K. (2003). The self-assembling properties of stearate ions in hydrotalcite clay composites. Langmuir 19, 9120-9126. doi: 10.1021/la0302448

Kistler, S. S. (1931). Coherent expanded aerogels and jellies. Nature 127, 741. doi: 10.1038/127741a0

Kojima, Y., Usuki, A., Kawasumi, M., Okada, A., Fukushima, Y., Kurauchi, et al. (1993). Mechanical properties of nylon 6-clay hybrid. J. Mater. Res. 8, 1179-1185. doi: 10.1557/JMR.1993.1185

Kucheyev, S. O., Stadermann, M., Shin, S. J., Satcher, J. H., Gammon, S. A., Letts, S. A., et al. (2012). Super-compressibility of ultralow-density nanoporous silica. Adv. Mater. 24, 776-780. doi: 10.1002/adma.201103561

LeBaron, P. C., Wang, Z., and Pinnavaia, T. J. (1999). Polymer-layered silicate nanocomposites: an overview. Appl. Clay Sci. 15, 11-29. doi: 10.1016/S01691317(99)00017-4

Longo, S., Vitillo, J. G., Daniel, C., and Guerra, G. (2013). Monolithic aerogels Based on poly(2, 6-diphenyl-1, 4-phenylene oxide) and syndiotactic polystyrene. ACS Appl. Mater. Interfaces 5, 5493-5499. doi: 10.1021/am400592z

Ma, J., Bilotti, E., Peijs, T., and Darr, J. A. (2007). Preparation of polypropylene/sepiolite nanocomposites using supercritical $\mathrm{CO}_{2}$ assisted mixing. Eur. Polym. J. 43, 4931-4939. doi: 10.1016/j.eurpolymj.2007.09.010

Mahesh, K. P. O., Sivakumar, M., Yamamoto, Y., Tsujita, Y., Yoshimizu, H., and Okamoto, S. (2005). Structure and properties of the mesophase of syndiotactit polystyrene. J. Membrane Sci. 262, 11-19. doi: 10.1016/j.memsci.2005.04.002

Malik, S., Roizard, D., and Guenet, J. M. (2006). Multiporous material from fibrillar syndiotactic polystyrene intercalates. Macromolecules 39, 5957-5959. doi: $10.1021 / \mathrm{ma} 060770 \mathrm{~g}$
Manfredi, C., Del Nobile, M. A., Mensitieri, G., Guerra, G., and Rapacciuolo, M. (1997). Vapor sorption in emptied clathrate samples of syndiotactic polystyrene. J. Polym. Sci. Polym. Phys. Ed. 35, 133-140. doi: 10.1002/(SICI)10990488(19970115)35:1<133::AID-POLB11>3.0.CO;2-E

Manias, E., Touny, A., Wu, L., Strawhecker, K., Lu, B., and Chung, T. C. (2001). Polypropylene/Montmorillonite nanocomposites. Review of the synthetic routes and materials properties. Chem. Mater. 13, 3516-3523. doi: $10.1021 / \mathrm{cm} 0110627$

Manitiu, M., Bellair, R. J., Horsch, S., Gulari, E., and Kannan, R. M. (2008). Supercritical carbon dioxide-processed dispersed polystyrene-clay nanocomposites. Macromolecules 41, 8038-8046. doi: 10.1021/ma801339g

Mauro, M., Maggio, M., Cipolletti, V., Galimberti, M., Longo, P., and Guerra, G. (2013). Graphite oxide intercalation compounds with rotator hexagonal order in the intercalated layers. Carbon 61, 395-403. doi: 10.1016/j.carbon.2013.05.023

Mensitieri, G., Venditto, V., and Guerra, G. (2003). Polymeric sensing films absorbing organic guests into a nanoporous host crystalline phase. Sens. Actuators B 92 255-261. doi: 10.1016/S0925-4005(03)00273-9

Milano, G., Venditto, V., Guerra, G., Cavallo, L., Ciambelli, P., and Sannino, D. (2001). Shape and volume of cavities in thermoplastic molecular sieves based on syndiotactic polystyrene. Chem. Mater. 13, 1506-1511. doi: 10.1021/ cm001089a

Musto, P., Mensitieri, G., Cotugno, S., Guerra, G., and Venditto, V. (2002). Probing by time-resolved FTIR spectroscopy mass transport, molecular interactions, and conformational ordering in the system chloroform-syndiotactic polystyrene. Macromolecules 35, 2296-2304. doi: 10.1021/ma011684d

Nguyen, Q. T., and Baird, D. G. (2007). An improved technique for exfoliating and dispersing nanoclay particles into polymer matrices using supercritical carbon dioxide. Polymer 48, 6923-6933. doi: 10.1016/j.polymer. 2007.09.015

Osman, M. A., Ernst, M., Meier, B. H., and Suter, U. W. (2002). Structure and molecular dynamics of alkane monolayers self-assembled on mica platelets J. Phys. Chem. B 106, 653-662. doi: 10.1021/jp0132376

Park, Y., Ayoko, G. A., and Frost, R. L. (2011). Characterisation of organiclays and adsorption of p-nitrophenol: environmental application. J. Colloid Interface Sci. 360, 440-456. doi: 10.1016/j.jcis.2011.04.085

Paul, D. R., and Robeson, L. M. (2008). Polymer nanotechnology: nanocomposites. Polymer 49, 3187-3204. doi: 10.1016/j.polymer.2008.04.017

Petraccone, V., Ruiz de Ballesteros, O., Tarallo, O., Rizzo, P., and Guerra, G. (2008). Nanoporous polymer crystals with cavities and channels. Chem. Mater. 20, 3663-3668. doi: 10.1021/cm800462h

Pilla, P., Cusano, A., Cutolo, A., Giordano, M., Mensitieri, G., Rizzo, P., et al. (2009) Molecular sensing by nanoporous crystalline polymers. Sensors 9, 9816-9857. doi: $10.3390 /$ s91209816

Pojanavaraphan, T., Liu, L., Ceylan, D., Okay, O., Magaraphan, R., and Schiraldi., D. A. (2011). Solution cross-linked natural rubber (NR)/clay aerogel composites. Macromolecules 44, 923-931. doi: 10.1021/ma102443k

Pojanavaraphan, T., Schiraldi, D. A., and Magaraphan, R. (2010). Mechanical, rheological, and swelling behavior of natural rubber/montmorillonite aerogels prepared by freeze-drying. Appl. Clay Sci. 50, 271-279. doi: 10.1016/j.clay.2010.08.020

Powder diffraction database 70-2151 International Centre for Diffraction Data. (1999). PCPDF win. Version 2.02.

Ray, S. S., and Okamoto, M. (2003). Polymer/layered silicate nanocomposites: a review from preparation to processing. Prog. Polym. Sci. 28, 1539-1641. doi: 10.1016/j.progpolymsci.2003.08.002

Rizzo, P., Daniel, C., De Girolamo Del Mauro, A., and Guerra, G. (2007). New host polymeric framework and related polar guest cocrystals. Chem. Mater. 19, 3864-3866. doi: 10.1021/cm071099c

Robello, D. R., Yamaguchi, N., Blanton, T., and Barnes, C. (2004). Spontaneous formation of an exfoliated polystyrene-clay nanocomposite using a star-shaped polymer. J. Am. Chem. Soc. 126, 8118-8119. doi: 10.1021/ ja048211h

Samaniuk, J., Litchfield, D., and Baird, D. (2009). Improving the exfoliation of layered silicate in a poly(ethylene terephthalate) matrix using supercritical carbon dioxide. Polym. Eng. Sci. 49, 2329-2341. doi: 10.1002/ pen. 21482

Schaefer, D. W., and Keefer, K. D. (1986). Restructuring of colloidal silica aggregates. Phys. Rev. Lett. 56, 2199. doi: 10.1103/PhysRevLett.56.2199 
Tarallo, O., Petraccone, V., Daniel, C., Fasano, G., Rizzo, P., and Guerra, G. (2012). A chiral co-crystalline form of poly(2, 6-dimethyl-1, 4-phenylene) oxide (PPO). J. Mater. Chem. 22, 11672-11680. doi: 10.1039/c2jm30907f

Thompson, M. R., Balogh, M. P., Speer, R. L., Fasulo, P. D., and Rodgers, W. R. (2009). In situ X-ray diffraction studies of alkyl quaternary ammonium montmorillonite in a $\mathrm{CO}_{2}$ enviroment. J. Chem. Phys. 130, 044705. doi: $10.1063 / 1.3065980$

Treece, M. A., and Oberhauser, J. P. (2007). Processing of polypropylene-clay nanocomposites: single screw extrusion with in-line supercritical carbon. J. Appl. Polym. Sci. 103, 884-892. doi: 10.1002/app.25226

Vaia, R. A., Ishii, H., and Giannelis, E. P. (1993). Synthesis and properties of two dimensional nanostructures by direct intercalation of polymer melts in layered silicates. Chem. Mater. 5, 1694-1696. doi: 10.1021/cm00036a004

Venditto, V., De Girolamo Del Mauro, A., Mensitieri, G., Milano, G., Musto, P., Rizzo, P., et al. (2006). Anisotropic guest diffusion in the $\delta$ crystalline host phase of syndiotactic polystyrene: transport kinetics in films with three different uniplanar orientations of the host phase. Chem. Mater. 18, 2205-2210. doi: $10.1021 / \mathrm{cm} 051657 \mathrm{~s}$

Wang, X., and Jana, S. C. (2013). Syndiotactic polystyrene aerogels containing multi-walled carbon nanotubes. Polymer 54, 750-759. doi: 10.1016/j.polymer.2012.12.025

Wang, Y., Alhassan, S. M., Yang, V. H., and Schiraldi, D. A. (2013). Polyether-blockamide copolymer/clay films prepared via a freeze-drying method. Compos. Part B 45, 625-630. doi: 10.1016/j.compositesb.2012.05.017
Wei, T. Y., Chen, C. H., Chang, K. H., Lu, S. Y., and Hu, C. C. (2010). A Costeffective supercapacitor material of ultrahigh specific capacitances: spinel nickel cobaltite aerogels from an epoxide-driven sol-gel process. Adv. Mater. 22, 347-351. doi: 10.1002/adma.200902175

Conflict of Interest Statement: The authors declare that the research was conducted in the absence of any commercial or financial relationships that could be construed as a potential conflict of interest.

Received: 29 August 2013; paper pending published: 20 September 2013; accepted: 14 October 2013; published online: 13 November 2013.

Citation: Longo S, Mauro M, Daniel C, Galimberti M and Guerra G (2013) Clay exfoliation and polymer/clay aerogels by supercritical carbon dioxide. Front. Chem. 1:28. doi: $10.3389 /$ fchem.2013.00028

This article was submitted to Polymer Chemistry, a section of the journal Frontiers in Chemistry.

Copyright (c) 2013 Longo, Mauro, Daniel, Galimberti and Guerra. This is an openaccess article distributed under the terms of the Creative Commons Attribution License (CC BY). The use, distribution or reproduction in other forums is permitted, provided the original author(s) or licensor are credited and that the original publication in this journal is cited, in accordance with accepted academic practice. No use, distribution or reproduction is permitted which does not comply with these terms. 